\title{
Strategi Belajar Mengajar Dengan Metode Thinks Pair Share Untuk Meningkatkan Prestasi Belajar Bahasa Indonesia Pada Siswa Kelas III SD Negeri 23 Dabatan Tahun Pelajaran 2016/2017
}

\author{
Ati Buatan
}

SD Negeri 23 Dabatan

\begin{abstract}
The success of learning was determined by many factors. One of them was teacher factor in conducting teaching learning process. Since, teacher directly could influence, guide and increase educational objectives. Teachers' role was very important and they were expected could have appropriate teaching model for their students. The objectives of this research were: (a) to know the improvement of students learning result after applying think pair share model and (b) to know the influence of think pair share model toward students' learning motivation. This research was Classroom Action Research which was conducted in 3 cycles. Every cycle consisted of planning, observation, action and reflection. The subject of this research was $3^{\text {rd }}$ grade students of SD 23 Dabatan. The data was collected using test and observation. Based on the data, the students' learning result from every cycle have increased, these were $68,18 \%$ on cycle I, $77,27 \%$ on cycle II, and $86,36 \%$ on cycle III. It could be concluded that think pair share method gave positive influence toward students' learning motivation and this method could be used as one of alternative teaching method on learning Bahasa Indonesia subject.
\end{abstract}

Keywords: Bahasa Indonesia, Think Pair Share, learning result, learning motivation, SD 23 Dabatan

Abstrak: Berhasilnya tujuan pembelajaran ditentukan oleh banyak faktor diantaranya adalah faktor guru dalam melaksanakan proses belajar mengajar, karena guru secara langsung dapat mempengaruhi, membina dan meningkatkan kecerdasan serta keterampilan siswa. Untuk mengatasi permasalahan di atas dan guna mencapai tujuan pendidikan secara maksimal, peran guru sangat penting dan diharapkan guru memiliki cara/model mengajar yang baik dan mampu memilih model pembelajaran yang tepat dan sesuai dengan konsep-konsep mata pelajaran yang akan disampaikan. Tujuan dari penelitian tindakan ini adalah: (a) Ingin mengetahui peningkatan prestasi belajar siswa setelah diterapkannya pembelajaran thinks pair share. (b) Ingin mengetahui pengaruh motivasi belajar siswa setelah diterapkannya metode pembelajaran thinks pair share. Penelitian ini menggunakan penelitian tindakan (action research) sebanyak tiga putaran. Setiap putaran terdiri dari empat tahap yaitu: rancangan, kegiatan dan pengamatan, refleksi, dan refisi. Sasaran penelitian ini adalah siswa kelas tiga. Data yang diperoleh berupa hasil tes formatif dan lembar observasi kegiatan belajar mengajar. Dari hasil analis didapatkan bahwa prestasi belajar siswa mengalami peningkatan dari siklus I sampai siklus III yaitu, siklus I $(68,18 \%)$, siklus II $(77,27 \%)$, siklus III $(86,36 \%)$. Kesimpulan dari penelitian ini adalah metode thinks pair share dapat berpengaruh positif terhadap motivasi belajar Siswa kelas tiga, serta metode pembelajaran ini dapat digunakan sebagai salah satu alternatif pembelajaran bahasa Indonesia.

Kata Kunci: Bahasa Indonesia, Think Pair Share, prestasi belajar, SD 23 Dabatan

\section{Pendahuluan}

Pembelajaran merupakan kegiatan utama sekolah, yang dalam pelaksanaannya sekolah diberi kebebasan memilih strategi, pendekatan, metode, dan teknik pembelajaran yang paling efektif, sesuai dengan karakteristik mata pelajaran, peserta didik, guru, serta kondisi nyata sumberdaya yang tersedia dan siap di dayagunakan di sekolah. Pemilihan dan pengembangan strategi, pendekatan, metode, dan teknik pembelajaranhakekatnya berpusat pada peserta didik (student centered), agar dapat melibatkan mereka 
secara aktif dan kreatif dalam pembelajaran. Pembelajaran harus menekankan pada praktek, dengan pendayagunaan masyarakat dan lingkungan sekitar sebagai sumber belajar.

Salah satu metode pembelajaran yang melibatkan siswa aktif adalah metode pembelajaran kooperatif. Pada dasarnya masing - masing siswa memiliki derajat potensi, latar belakang historis, serta harapan masa depan yang berbeda - beda. Karena adanya perbedaan maka dapat saling silih asah. Pembelajaran kooperatif secara sadar menciptakan interaksi yang silih salah sehingga sumber belajar bagi siswa bukan hanya guru dan buku ajar tetapi juga sesama manusia.

Bagi sebagian siswa, pembelajaran Bahasa Indonesia sangat membosankan karena mereka sudah merasa bisa dan penyampaian materi yang kurang menarik sehingga secara tidak langsung siswa menjadi lemah dalam penangkapan materi tersebut. Penulis sebagai guru Bahasa Indonesia sangat merasakan problem pembelajaran yang terjadi selama ini. Karena dalam pembelajaran proses belajar mengajar masih di dominasi oleh guru (teacher centered), siswa kurang di libatkan secara aktif dalam pembelajaran. Selama ini guru semata - mata hanya memberikan pengetahuan kepada siswa tanpa membuat suatu informasi menjadi bermakna dan relevan bagi siswa sehingga siswa kesulitan membangun konsep di dalam pikirannya sendiri.

\section{Metode Penelitian}

\subsection{Desain Penelitian}

Penelitian ini merupakan penelitian tindakan (action research), karena penelitian dilakukan untuk memecahkan masalah pembelajaran di kelas. Penelitian ini juga termasuk penelitian deskriptif, sebab menggambarkan bagaimana suatu teknik pembelajaran diterapkan dan bagaimana hasil yang diinginkan dapat dicapai.

\subsection{Tempat dan Waktu Penelitian}

Tempat penelitian adalah tempat yang digunakan dalam melakukan penelitian untuk memperoleh data yang diinginkan. Penelitian ini bertempat di kelas tiga tahun pelajaran 2016/2017. Waktu penelitian adalah waktu berlangsungnya penelitian atau saat penelitian ini dilangsungkan. Penelitian ini dilaksanakan pada bulan September semester gasal 2016/2017.

\subsection{Teknik Pengumpulan Data}

Data-data yang diperlukan dalam penelitian ini diperoleh melalui observasi pengolahan pembelajaran thinks pair share, observasi aktivitas siswa dan guru, dan tes formatif.

\subsection{Teknik Analisis Data}

Untuk mengalisis tingkat keberhasilan atau persentase keberhasilan siswa setelah proses belajar mengajar setiap putarannya dilakukan dengan cara memberikan evaluasi berupa soal tes tertulis pada setiap akhir putaran. 
Analisis ini dihitung dengan menggunakan statistik sederhana yaitu:

1. Untuk menilai ulangan atu tes formatif

Peneliti melakukan penjumlahan nilai yang diperoleh siswa, yang selanjutnya dibagi dengan jumlah siswa yang ada di kelas tersebut sehingga diperoleh rata-rata tes formatif dapat dirumuskan:

$$
\bar{X}=\frac{\sum X}{\sum N}
$$

$$
\text { Dengan } \quad \begin{aligned}
: \bar{X} & =\text { Nilai rata-rata } \\
\Sigma \mathrm{X} & =\text { Jumlah semua nilai siswa } \\
\Sigma \mathrm{N} & =\text { Jumlah siswa }
\end{aligned}
$$

2. Untuk ketuntasan belajar

Ada dua kategori ketuntasan belajar yaitu secara perorangan dan secara klasikal. Berdasarkan petunjuk pelaksanaan belajar mengajar kurikulum 1994 (Depdikbud, 1994), yaitu seorang siswa telah tuntas belajar bila telah mencapai skor $65 \%$ atau nilai 65 , dan kelas disebut tuntas belajar bila di kelas tersebut terdapat $85 \%$ yang telah mencapai daya serap lebih dari sama dengan $65 \%$. Untuk menghitung persentase ketuntasan belajar digunakan rumus sebagai berikut:

$$
P=\frac{\sum \text { Siswa.yang.tuntas.belajar }}{\sum \text { Siswa }} \times 100 \%
$$

\section{Hasil dan Pembahasan}

\subsection{Hasil Penelitian}

\subsubsection{Analisis Item Butir Soal}

Sebelum melaksanakan pengambilan data melalui instrumen penelitian berupa tes dan mendapatkan tes yang baik, maka data tes tersebut diuji dan dianalisi. Uji coba dilakukan pada siswa di luar sasaran penelitian. Analisis tes yang dilakukan meliputi:

1. Validitas

Validitas butir soal dimaksudkan untuk mengetahui kelayakan tes sehingga dapat digunakan sebagai instrument dalam penelitian ini. Dari perhitungan 46 soal diperoleh 16 soal tidak valid dan 30 soal valid. Hasil dari validits soal-soal dirangkum dalam tabel di bawah ini.

Tabel 3.1. Soal Valid dan Tidak Valid Tes Formatif Siswa

\begin{tabular}{cc}
\hline Soal Valid & Soal Tidak Valid \\
\hline $1,2,5,6,7,9,10,11,12,13,14,17,19,21,23,25$, & $3,4,8,15,16,18,20,22$,
\end{tabular}


$26,27,28,29,30,36,37,38,39,41,42,43,44,45 \quad 24,31,32,33,34,35,40$,

46

2. Reliabilitas

Soal-soal yang telah memenuhi syarat validitas diuji reliabilitasnya. Dari hasil perhitungan diperoleh koefisien reliabilitas $r_{11}$ sebesar 0, 775. Harga ini lebih besar dari harga $r$ product moment. Untuk jumlah siswa $(\mathrm{N}=22)$ dengan $\mathrm{r}(95 \%)=0,423$. Dengan demikian soalsoal tes yang digunakan telah memenuhi syarat reliabilitas.

3. Taraf Kesukaran (P)

Taraf kesukaran digunakan untuk mengetahui tingkat kesukaran soal. Hasil analisis menunjukkan dari 46 soal yang diuji terdapat:

- 20 soal mudah

- 16 soal sedang

- 10 soal sukar

4. Daya Pembeda

Analisis daya pembeda dilakukan untuk mengetahui kemampuan soal dalam membedakan siswa yang berkemampuan tinggi dengan siswa yang berkemampuan rendah.

Dari hasil analisis daya pembeda diperoleh soal yang berkriteria jelek sebanyak 14 soal, berkriteria cukup 20 soal, berkreteria baik 10 soal, dan yang berkriteria tidak baik 2 soal. Dengan demikian soal-soal tes yang digunakan telah memenuhi syara-syarat validitas, reliabilitas, taraf kesukaran, dan daya pembeda.

\subsubsection{Hasil Tiap Siklus}

Pada akhir proses belajar mengajar siswa diberi tes formatif I dengan tujuan untuk mengetahui tingkat keberhasilan siswa dalam proses belajar mengajar yang telah dilakukan. Adapun data hasil penelitian pada siklus I adalah sebagai berikut:

Tabel 3.2. Hasil Tes Formatif Siswa Pada Siklus I

\begin{tabular}{cccccccc}
\hline \multirow{2}{*}{ No. Urut } & \multirow{2}{*}{ Nilai } & \multicolumn{2}{c}{ Keterangan } & & \multicolumn{2}{c}{ Keterangan } \\
\cline { 6 - 7 } No. Urut & Nilai & T & TT \\
\hline 1 & 60 & & $\sqrt{n}$ & 12 & 60 & & $\sqrt{ }$ \\
2 & 70 & $\sqrt{ }$ & & 13 & 80 & $\sqrt{ }$ \\
3 & 70 & $\sqrt{ }$ & & 14 & 70 & $\sqrt{ }$ \\
4 & 60 & & $\sqrt{ }$ & 15 & 80 & $\sqrt{ }$
\end{tabular}




\begin{tabular}{|c|c|c|c|c|c|c|c|}
\hline 5 & 80 & $\sqrt{ }$ & & 16 & 70 & $\sqrt{ }$ & \\
\hline 6 & 80 & $\sqrt{ }$ & & 17 & 90 & $\sqrt{ }$ & \\
\hline 7 & 70 & $\sqrt{ }$ & & 18 & 60 & & $\sqrt{ }$ \\
\hline 8 & 70 & $\sqrt{ }$ & & 19 & 60 & & $\sqrt{ }$ \\
\hline 9 & 60 & & $\sqrt{ }$ & 20 & 70 & $\sqrt{ }$ & \\
\hline 10 & 80 & $\sqrt{ }$ & & 21 & 70 & $\sqrt{ }$ & \\
\hline 11 & 50 & & $\sqrt{ }$ & 22 & 60 & & $\sqrt{ }$ \\
\hline Jumlah & 750 & 7 & 4 & Jumlah & 770 & 8 & 3 \\
\hline
\end{tabular}

Jumlah Skor 1520

Jumlah Skor Maksimal Ideal 2200

Rata-Rata Skor Tercapai 69,09

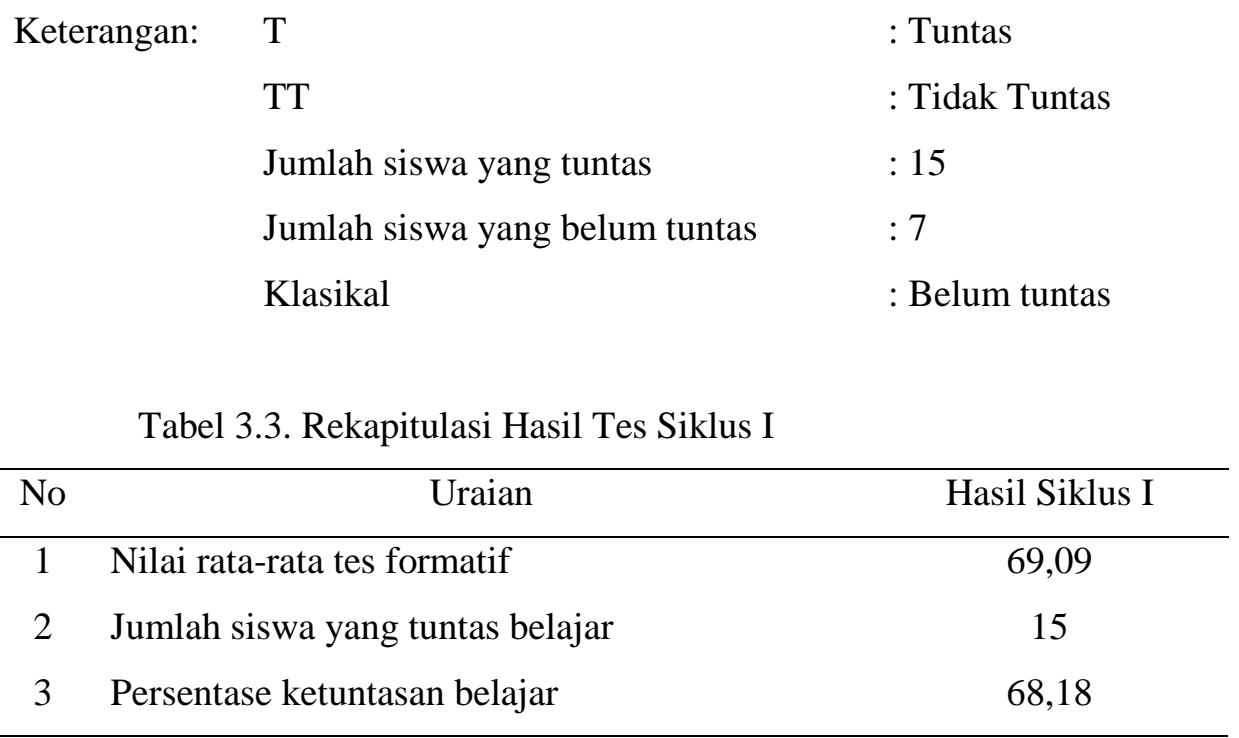

Dari tabel di atas dapat dijelaskan bahwa dengan menerapkan metode pembelajaran thinks pair share diperoleh nilai rata-rata prestasi belajar siswa adalah 69,09 dan ketuntasan belajar mencapai 68,18\% atau ada 15 siswa dari 22 siswa sudah tuntas belajar. Hasil tersebut menunjukkan bahwa pada siklus pertama secara klasikal siswa belum tuntas belajar, karena siswa yang memperoleh nilai $\geq 65$ hanya sebesar 68,18\% lebih kecil dari persentase ketuntasan yang dikehendaki yaitu sebesar $85 \%$. Hal ini disebabkan karena siswa masih merasa baru dan belum mengerti apa yang dimaksudkan dan digunakan guru dengan menerapkan metode pembelajaran thinks pair share.

Tabel 3.4. Hasil Tes Formatif Siswa Pada Siklus II

\begin{tabular}{|c|c|c|c|c|c|}
\hline No. Urut & Nilai & Keterangan & No. Urut & Nilai & Keterangan \\
\hline
\end{tabular}




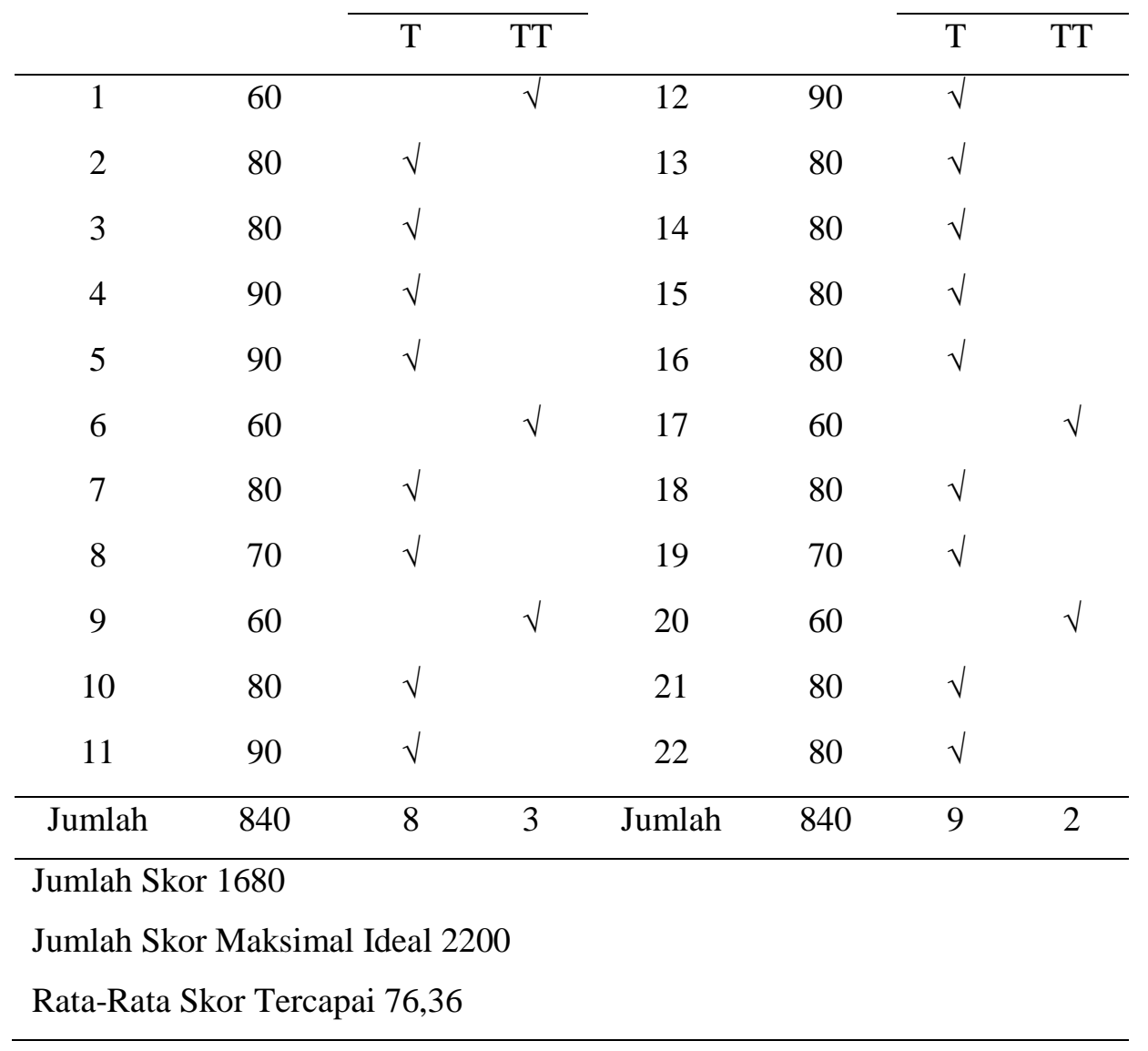

Tabel 3.5. Rekapitulasi Hasil Tes Siklus II

\begin{tabular}{clc}
\hline No & \multicolumn{1}{c}{ Uraian } & Hasil Siklus II \\
\hline 1 & Nilai rata-rata tes formatif & 76,36 \\
2 & Jumlah siswa yang tuntas belajar & 17 \\
3 & Persentase ketuntasan belajar & 77,27 \\
\hline
\end{tabular}

Dari tabel di atas diperoleh nilai rata-rata prestasi belajar siswa adalah 76,36 dan ketuntasan belajar mencapai 77,27\% atau ada 17 siswa dari 22 siswa sudah tuntas belajar. Hasil ini menunjukkan bahwa pada siklus II ini ketuntasan belajar secara klasikal telah megalami peningkatan sedikit lebih baik dari siklus I. Adanya peningkatan hasil belajar siswa ini karena setelah guru menginformasikan bahwa setiap akhir pelajaran akan selalu diadakan tes sehingga pada pertemuan berikutnya siswa lebih termotivasi untuk belajar. Selain itu siswa juga sudah mulai mengerti apa yang dimaksudkan dan diinginkan guru dengan menerapkan metode pembelajaran thinks pair share.

Tabel 3.6. Hasil Tes Formatif Siswa Pada Siklus III

\begin{tabular}{|c|c|c|c|c|c|}
\hline No. Urut & Nilai & Keterangan & No. Urut & Nilai & Keterangan \\
\hline
\end{tabular}




\begin{tabular}{|c|c|c|c|c|c|c|c|}
\hline & & \multirow{2}{*}{\multicolumn{2}{|c|}{$\begin{array}{ll}\mathrm{T} & \mathrm{TT}\end{array}$}} & & & \multirow{3}{*}{$\begin{array}{l}\mathrm{T} \\
\sqrt{ }\end{array}$} & \multirow{3}{*}{ TT } \\
\hline & & & & & & & \\
\hline 1 & 90 & $\sqrt{ }$ & & 12 & 90 & & \\
\hline 2 & 90 & $\sqrt{ }$ & & 13 & 90 & $\sqrt{ }$ & \\
\hline 3 & 90 & $\sqrt{ }$ & & 14 & 90 & $\sqrt{ }$ & \\
\hline 4 & 80 & $\sqrt{ }$ & & 15 & 60 & & $\sqrt{ }$ \\
\hline 5 & 90 & $\sqrt{ }$ & & 16 & 90 & $\sqrt{ }$ & \\
\hline 6 & 80 & $\sqrt{ }$ & & 17 & 80 & $\sqrt{ }$ & \\
\hline 7 & 90 & $\sqrt{ }$ & & 18 & 70 & $\sqrt{ }$ & \\
\hline 8 & 60 & & $\sqrt{ }$ & 19 & 70 & $\sqrt{ }$ & \\
\hline 9 & 90 & $\sqrt{ }$ & & 20 & 80 & $\sqrt{ }$ & \\
\hline 10 & 90 & $\sqrt{ }$ & & 21 & 90 & $\sqrt{ }$ & \\
\hline 11 & 60 & & $\sqrt{ }$ & 22 & 80 & $\sqrt{ }$ & \\
\hline nlah & 910 & 9 & 2 & Jumlah & 890 & 10 & 1 \\
\hline
\end{tabular}

Jumlah Skor 1800

Jumlah Skor Maksimal Ideal 2200

Rata-Rata Skor Tercapai 81,82

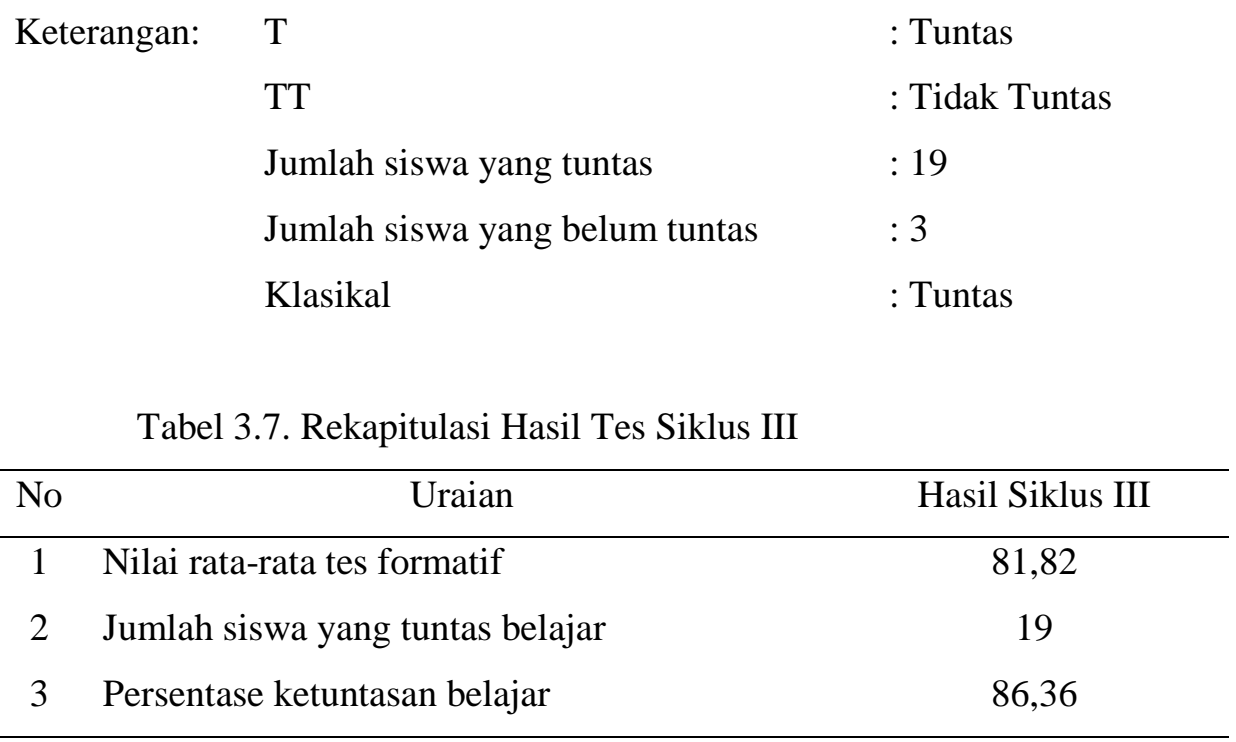

Berdasarkan tabel diatas diperoleh nilai rata-rata tes formatif sebesar 81,82 dan dari 22 siswa yang telah tuntas sebanyak 19 siswa dan 3 siswa belum mencapai ketuntasan belajar. Maka secara klasikal ketuntasan belajar yang telah tercapai sebesar 86,36\% (termasuk kategori tuntas). Hasil pada siklus III ini mengalami peningkatan lebih baik dari siklus II. Adanya peningkatan hasil belajar pada 
siklus III ini dipengaruhi oleh adanya peningkatan kemampuan guru dalam menerapkan pembelajaran thinks pair share sehingga siswa menjadi lebih terbiasa dengan pembelajaran seperti ini sehingga siswa lebih mudah dalam memahami materi yang telah diberikan. Pada siklus III ini ketuntasan secara klasikal telah tercapai, sehingga penelitian ini hanya sampai pada siklus III.

\subsection{Pembahasan}

Melalui hasil peneilitian ini menunjukkan bahwa pembelajaran thinks pair share memiliki dampak positif dalam meningkatkan prestasi belajar siswa. Hal ini dapat dilihat dari semakin mantapnya pemahaman siswa terhadap materi yang disampaikan guru (ketuntasan belajar meningkat dari sklus I, II, dan II) yaitu masing-masing 68,18\%, 77,27\%, dan 86,36\%. Pada siklus III ketuntasan belajar siswa secara klasikal telah tercapai.

Berdasarkan analisis data, diperoleh aktivitas siswa dalam proses pembelajaran thinks pair share dalam setiap siklus mengalami peningkatan. Hal ini berdampak positif terhadap prestasi belajar siswa yaitu dapat ditunjukkan dengan meningkatnya nilai rata-rata siswa pada setiap siklus yang terus mengalami peningkatan.

Berdasarkan analisis data, diperoleh aktivitas siswa dalam proses pembelajaran bahasa Indonesia pada pokok bahasan Membaca yang paling dominan adalah bekerja dengan menggunakan alat/media, mendengarkan/ memperhatikan penjelasan guru, dan diskusi antar siswa/antara siswa dengan guru. Jadi dapat dikatakan bahwa aktivitas siswa dapat dikategorikan aktif.

Sedangkan untuk aktivitas guru selama pembelajaran telah melaksanakan langah-langkah pembelajaran thinks pair share dengan baik. Hal ini terlihat dari aktivitas guru yang muncul di antaranya aktivitas membimbing dan mengamati siswa dalam mengerjakan kegiatan LKS/menemukan konsep, menjelaskan/melatih menggunakan alat, memberi umpan balik/evaluasi/tanya jawab dimana prosentase untuk aktivitas di atas cukup besar.

\section{Simpulan dan Saran}

\subsection{Kesimpulan}

Dari hasil kegiatan pembelajaran yang telah dilakukan selama tiga siklus, dan berdasarkan seluruh pembahasan serta analisis yang telah dilakukan dapat disimpulkan sebagai berikut:

1. Pembelajaran dengan thinks pair share memiliki dampak positif dalam meningkatkan prestasi belajar siswa yang ditandai dengan peningkatan ketuntasan belajar siswa dalam setiap siklus, yaitu siklus I (68,18\%), siklus II (77,27\%), siklus III (86,36\%).

2. Penerapan metode pembelajaran thinks pair share mempunyai pengaruh positif, yaitu dapat meningkatkan motivasi belajar siswa yang ditunjukan dengan hasil wawancara dengan sebagian 
siswa, rata-rata jawaban siswa menyatakan bahwa siswa tertarik dan berminat dengan metode pembelajaran thinks pair share sehingga mereka menjadi termotivasi untuk belajar.

\subsection{Saran}

Dari hasil penelitian yang diperoleh dari uraian sebelumnya agar proses belajar mengajar bahasa Indonesia lebih efektif dan lebih memberikan hasil yang optimal bagi siswa, maka disampaikan saran sebagai berikut:

1. Untuk melaksanakan model thinks pair share memerlukan persiapan yang cukup matang, sehingga guru harus mampu menentukan atau memilih topik yang benar-benar bisa diterapkan dengan model thinks pair share dalam proses belajar mengajar sehingga diperoleh hasil yang optimal.

2. Dalam rangka meningkatkan prestasi belajar siswa, guru hendaknya lebih sering melatih siswa dengan berbagai metode pembelajaran, walau dalam taraf yang sederhana, dimana siswa nantinya dapat menemukan pengetahuan baru, memperoleh konsep dan keterampilan, sehingga siswa berhasil atau mampu memecahkan masalah-masalah yang dihadapinya.

3. Perlu adanya penelitian yang lebih lanjut, karena hasil penelitian ini hanya dilakuakan di kelas tiga SD Negeri 23 Dabatan tahun pelajaran 2016/2017.

\section{Daftar Pustaka}

Arikunto, Suharsimi. 1997. Dasar-dasar Evaluasi Pendidikan. Jakarta: Bumi Aksara.

Berg, Euwe Vd. 1991. Miskonsepsi bahasa Indonesia dan Remidi Salatiga: Universitas Kristen Satya Wacana.

Hamalik, Oemar. 2002. Psikologi Belajar dan Mengajar. Bandung: Sinar Baru Algesindo.

Joyce, Bruce dan Weil, Marsh. 1972. Models of Teaching Model. Boston: A Liyn dan Bacon. Masriyah. 1999. Analisis Butir Tes. Surabaya: Universitas Press.

Mukhlis, Abdul. (Ed). 2000. Penelitian Tindakan Kelas. Makalah Panitia Pelatihan Penulisan Karya Ilmiah untuk Guru-guru se-Kabupaten Tuban.

Nur, Moh. 2016. Pemotivasian Siswa untuk Belajar. Surabaya. University Press. Universitas Negeri Surabaya.

Soedjadi, dkk. 2000. Pedoman Penulisan dan Ujian Skripsi. Surabaya; Unesa Universitas Press.

Suryosubroto, B. 1997. Proses Belajar Mengajar di Sekolah. Jakarta: PT. Rineksa Cipta.

Usman, Uzer. 2000. Menjadi Guru Profesional. Bandung: PT. Remaja Rosdakarya.

Widoko. 2002. Metode Pembelajaran Konsep. Surabaya: Universitas Negeri Surabaya. 